\title{
TEORIAS DA DEMOCRACIA E O REFERENDO CATALÃO DE 2017
}

\author{
TEORÍAS DE LA DEMOCRACIA Y EL REFERÉNDUM CATALÁN DE 2017
}

THEORIES OF DEMOCRACY AND THE CATALAN REFERENDUM OF 2017

\author{
Caio MOTTA ${ }^{1}$
}

\begin{abstract}
RESUMO: Neste trabalho, começaremos introduzindo as principais informações sobre todo o processo de referendo até o mês de novembro de 2017, incluindo, também, informações sobre a situação econômica, social e cultural, da Catalunha. Após isso, introduziremos uma série de teorias da democracia que nos permitem analisar o processo tanto de uma via positiva quanto de uma via negativa. Notar-se-á que a maioria dos autores foi utilizada de forma favorável à independência, mas argumentar-se-á que certas visões com um caráter multicultural nos levam para problemas práticos de difícil resolução, nos levando a procurar como solução ou uma postura participacionista de cunho liberal ou uma postura multicultural moderada, ambas as críticas ao processo
\end{abstract}

PALAVRAS-CHAVE: Catalunha. Referendo. Multiculturalismo. Liberalismo.

RESUMEN: En este trabajo, comenzaremos introduciendo las principales informaciones sobre todo el proceso de referéndum hasta noviembre de 2017, incluyendo también informaciones sobre la situación económica, social y cultural de Cataluña. Después de eso, introduciremos una serie de teorías de la democracia que nos permiten analizar el proceso tanto de una vía positiva como de una vía negativa. Se notará que la mayoría de los autores fueron utilizados de forma favorable a la independencia, pero se argumentará que ciertas visiones con un carácter multicultural nos llevan a problemas prácticos de difícil resolución, llevándonos a buscar como solución o una postura participacionista de carácter liberal o una postura multicultural moderada, ambas críticas al proceso.

PALABRAS CLAVE: Cataluña. Referéndum. Multiculturalismo. Liberalismo.

ABSTRACT: In this paper, we begin introducing the most relevant data about the Catalan independence referendum until november of 2017, including, also, information about the economic, social, and cultural, aspects of Catalonia. After this, we're going to introduce a series theories of democracy that enable us to analyse the hole process within a positive and negative framework. It's going to be clear that the majority of authors were used to shed a positive light on the referendum, but it's the opposite that's going to be defended: certain multicultural views lead us to pratical problems of hard resolution, making us look for a liberal participacionism or a moderated multicultural view, both critical of the process.

KEYWORDS: Catalonia. Referendum. Multiculturalism. Liberalism.

${ }^{1}$ Universidade Estadual Paulista - (Unesp), Faculdade de Ciências e Letras, Araraquara - SP - Brasil. Graduando em Ciências Sociais. E-mail: caiomotta36@yahoo.com. 


\section{Introdução}

No dia 01/10/2017, na Catalunha, uma das regiões mais ricas e industrializadas da Espanha - mas, ao mesmo tempo, uma das mais endividadas; situação piorada por medidas de austeridade que podem ter influenciado no desejo por independência -, dois milhões de pessoas votaram para criar uma nação própria, separando-se da Espanha. O governo espanhol já tinha declarado anteriormente que o voto era ilegal, acusando o parlamento Catalão de cometer uma "atrocidade constitucional e democrática" ao aprovar a legislação que permitiu a votação. No dia 06/09/2017, a coalizão pró-independência - que tinha uma maioria no parlamento Catalão - conseguiu que o referendo fosse aprovado a despeito das objeções dos membros do parlamento da oposição, que argumentaram que não houve o cumprimento adequado dos procedimentos parlamentares. No final, a legislação foi aprovada por 72 votos após 52 membros de a oposição terem se retirado da câmara como forma de protesto2. No dia 07/09/2017, a Corte Constitucional espanhola declarou a ilegalidade do voto e que ele não devia prosseguir (Wildman, 2017).

O sucesso inicial de Carles Puigdemont e seu governo regional da Catalunha teve que também superar outra dificuldade: a própria constituição espanhola de 1978, aprovada por mais de 90\% dos eleitores catalãos (The Economist, 2017). Portanto, o plebiscito que ocorreu no dia 01/10 já era ilegal em virtude do conteúdo desta constituição democrática no que concerne à autonomia das regiões. Ainda que as tenha conferido grande autonomia, a constituição estabeleceu "a unidade indissolúvel da nação espanhola". Somente o Parlamento tem poder para mudar a constituição, tornando, então, o referendo iniciado por Puidgemont ilegal; e Mariano Rajoy, o conservador primeiro-ministro espanhol, tinha se colocado como oposto ao referendo.

A título de contextualização, analisaremos alguns fatores característicos da Catalunha que podem ter influenciado sua independência. A região conta com a habitação de 7.5 milhões de pessoas e tem como capital uma das cidades mais ricas de todas as províncias espanholas: Barcelona. Além do relevante aspecto econômico, a Catalunha tem uma língua própria (Catalão), um sistema educacional, e tradições literárias e culturais características. Sua vontade pela independência não é um acontecimento recente meramente influenciado por movimentos separatistas de outros lugares, na verdade, podemos destacar dois momentos históricos que podem ser entendidos como originários de tal vontade: primeiro, há quase 80 anos atrás, quando o ditador Francisco Franco tentou suprimir a língua e cultura catalã; e, mais anteriormente, desde o séc. XVIII, quando a região foi incluída pela Espanha. Com estas 
informações, podemos entender que, mesmo que a região não fosse independente, sua população tinha orgulho de sua língua e traços culturais distintos, próprios à Catalunha, e sua autonomia sempre foi algo resguardado, mesmo que não efetivada na prática.

Relacionando a Catalunha com a Espanha, vemos que o fato da região ter uma cultura e língua própria não a diferencia das outras regiões. Várias regiões da Espanha têm suas heranças culturais distintas, implicando até mesmo no fato do hino nacional espanhol não ter letras, isto se dando pela incapacidade das diversas regiões com suas culturas próprias chegarem a um acordo sobre o conteúdo dessas. Mesmo com essas diferenças se espalhando por toda Espanha, podemos observar aspectos idiossincráticos à Catalunha. Historicamente, a região teve seu próprio governo regional, aprofundando o sentimento que eles não pertencem à Espanha. Este governo regional - chamado Generalitat - expressa poder considerável na educação, saúde, e taxação da região. Contudo, eles ainda pagam impostos para Madrid, fazendo com que políticos pró-independência argumentem que a Espanha faz uso de mecanismos injustos de distribuição de renda para se aproveitarem das áreas mais prósperas. Isto faz parte de uma raiva geral com o governo Espanhol, com os catalãos afirmando que não é visto nenhum retorno deste dinheiro recolhido como imposto, gerando o sentimento que o governo espanhol é um óbice e que eles estariam melhores sem ele. Este sentimento é reforçado quando se percebe a importância do papel desempenhado pela economia catalã na recuperação econômica de Madrid, criando-se a impressão que os vários dos benefícios produzidos por ser a maior economia da Espanha (com um PIB de 211.915M. $€$ euros), respondendo (com 266 bilhões de euros) por quase um quinto da economia do país, são usurpados por terceiros. Mesmo com estes argumentos, o governo espanhol foi pungente ao afirmar que não haveria referendo - para ele, o voto seria ilegal, unilateral e inconstitucional.

Deste modo, o aspecto econômico é um dos aspectos essenciais a serem compreendidos. De acordo com a economista Elisenda Paluzie, os catalãos representam $16 \%$ da população do país, mas estes mesmos cidadãos contribuem com $20 \%$ nos impostos espanhóis, e recebem de volta $14 \%$ em gastos públicos. Portanto, a independência catalã seria uma perda considerável para o país, ainda mais quando se leva em conta o quanto que a região contribui com a economia do país (Benavides, 2017). Porém, mesmo que motivações econômicas desenvolvam parte do importante desejo de independência, tais motivos não foram levados em conta pelo governo espanhol, que poderiam ter considerado o diálogo como principal forma de conter um sentimento que, se concretizado, pode gerar efeitos danosos na economia. De fato, o que se viu foi a completa desconsideração do diálogo em favor de formas autoritárias de repressão. Duas semanas antes de o referendo ter acontecido, cerca de 
40.000 pessoas se reuniram fora da agência governamental do governo Catalão no centro de Barcelona para protestar a prisão de funcionários e oficiais do governo, além de simpatizantes de toda espécie. A reação do primeiro ministro espanhol Mariano Rajoy seguiu um tom condenatório, preferindo enfatizar que os líderes separatistas deveriam cessar aquilo que ele considerava "desobediência" e "escalada do radicalismo", reafirmando que o voto contradizia a constituição espanhola, pois esta afirma que o país indivisível.

A votação, que ocorreu no dia 01/10/2017, foi permeada pelo caos e embate entre a polícia nacional e indivíduos pró-independência. A ação truculenta também foi direcionada à própria possibilidade das pessoas votarem, pois, além de usarem balas de borracha contra os eleitores, também tentaram destruir locais de votação e confiscar as urnas. No final, o governo catalão afirmou que $90 \%$ daqueles que votaram apoiaram a independência, apesar da votação ter sido boicotada pelos oponentes da independência, fazendo com que mais da metade dos catalãos não votassem. Ou seja, aqueles que votaram foram aqueles já motivados pela independência. Assim, criou-se também uma divisão dentro da própria Catalunha, divisão esta que antes estava circunscrita à Espanha. Madrid também argumentou que o voto não usou um censo válido, e não fez justiça às garantias de monitoramento e recontagem. Os dados da votação são os seguintes:

Quadro 1: Dados da Votação Catalunha

\begin{tabular}{|l|c|c|}
\hline \multicolumn{3}{|l|}{$\begin{array}{l}\text { Você quer que a Catalunha se torne um estado independente na forma de uma } \\
\text { república? }\end{array}$} \\
\hline \multicolumn{2}{|c|}{ Resultados } \\
\hline & Votos & $92.01 \%$ \\
\hline Sim: & $\mathbf{2 , 0 4 4 , 0 3 8}$ & $7,99 \%$ \\
\hline Não: & 177,547 & $97,17 \%$ \\
\hline Votos válidos & $2,221,585$ & $2,83 \%$ \\
\hline Inválidos ou nulos & 64,632 & $\mathbf{1 0 0 \%}$ \\
\hline Votos totais & $\mathbf{2 , 2 8 6 , 2 1 7}$ & $\mathbf{4 3 , 0 3 \%}$ \\
\hline Eleitores & $\mathbf{5 , 3 1 3 , 5 6 4}$ & \\
registrados/participação & & \\
\hline
\end{tabular}

Fonte: Governo da Catalunha (2017-2018)

Como consequência deste voto, o Parlamento catalão votou a favor da declaração da independência; Madrid agiu para dissolver o governo regional e impor seu próprio regime; e o 
líder catalão Carles Puidgemont afirmou em Bruxelas que não tinha uma data exata de saída, além de enfrentar acusações criminais na Espanha que podem o prender por décadas.

\section{Análise}

Podemos, agora que reunimos certa quantidade de informações e dados, introduzir algumas das formulações teóricas necessárias a uma maior compreensão do assunto. Pateman (1970) realiza uma discussão interessante sobre as teorias recentes da democracia que têm em comum a crítica do "mito clássico" e certo ceticismo com relação à participação democrática. Pateman argumentará que tais teorias criaram um espantalho na forma do "mito clássico" e o atacaram sem sequer considerar se este mito correspondia a alguma verdadeira formulação teórica. Seguindo Schumpeter (1984), um dos autores que criticou este mito presente naquilo que ele considerava a doutrina clássica da democracia, pode-se definir esta a partir de dois aspectos: a existência e possibilidade de alcançar o bem comum e a vontade do povo. Supôsse, além da existência do bem comum, a facilidade com que pessoas normais podem lhe definir e entender. Schumpeter encarou isto como impraticável, pois, na realidade, o que se vê é a incapacidade das pessoas formularem preferências até mesmos individuais, deixando-se levarem por variáveis não racionais ou fazendo decisões equivocadas devido à falta de informações relevantes.

Se tomarmos e interpretarmos o referendo da Catalunha à vista de Schumpeter e outros autores que fizeram críticas a este mito, como Michels (1982), provavelmente concluiríamos que se deixou a uma população apática e sem o devido conhecimento uma decisão de extrema importância e com consequências tanto imediatas quanto de longo prazo. Esta decisão, se admitirmos que ela mesma é válida, deveria ficar restrita a uma oligarquia que tem a capacidade técnica e racional para consolidar um parecer, não às mãos de uma população passível de manipulação e guiada diretamente por sentimentos. Todavia, Pateman, ao analisar vários representantes desta teoria, formula sua teoria da democracia participativa. Ela é " [...] construída em torno da afirmação central de que os indivíduos e suas instituições não podem ser considerados isoladamente" (PATEMAN, 1970, p. 60). A autora afirma que se deve treinar a capacidade participativa dos indivíduos para que elas possam participar em outras esferas além daquelas instituições representativas a nível nacional, concebendo a função participativa numa democracia como algo educativo, aprimorando as capacidades técnicas e psicológicas dos indivíduos. Desta forma, a participação torna-se essencial à 
democracia, pois sem ela, sem uma sociedade participativa, tem-se uma democracia deficitária, incompleta.

Habermas (1995), realiza um processo de comparação semelhante, mas, desta vez, analisa os modelos republicanos e liberais de democracia para, no final, formar o seu conceito de política deliberativa. O referendo e a história da Catalunha poderiam ser compreendidos dentro de um modelo normativo republicano, pois é nele, e não no liberal, que surge uma forte preocupação com questões relativas à autocompreensão ética dos grupos sociais. No âmbito da autodeterminação cidadã, o republicanismo pressupõe “(...) uma base de sociedade civil autônoma, independente tanto da administração pública como do intercâmbio privado, que protegeria a comunicação política da absorção pelo aparato estatal ou da assimilação à estrutura do mercado" (HABERMAS, 1995, p. 40). À medida que ser cidadão republicano não passa somente por um conjunto de liberdades negativas que marcam a ausência de interferência estatal e de terceiros, mas sim por uma liberdade positiva que vê na prática da participação a produção de um cidadão livre e autônomo, capaz de se autodeterminar, o referendo pode ser entendido como manifestação da liberdade positiva dos cidadãos catalãos. O republicanismo pode oferecer uma interpretação positiva de todo processo enquanto que vermos o referendo como aspecto importante no desenvolvimento da autocompreensão ética dos grupos sociais catalãos que não se identificam como espanhóis.

O que esta exposição nos elucida sobre o caso da Catalunha? Antes de responder, voltemos a 2003. Já neste ano partidos que requisitaram a reforma do estatuto catalão sobre sua própria autonomia, regulando a habilidade da região ao autogoverno, ganham $88 \%$ das cadeiras na eleição regional. E em 2005 o parlamento Catalão aprovou a reforma do estatuto sobre a autonomia da região com o apoio de 120 membros do parlamento, e 15 votos contra. Esta reforma procurava expandir os poderes do governo regional, reconhecendo a Catalunha como uma nação e dando prioridade à linguagem catalã sobre a espanhola, além de estabelecer as áreas nas quais o governo regional iria ter competência exclusiva e um novo corpo responsável pela coleta de impostos. Retornando a Pateman, podemos considerar o referendo como manifestação da educação democrática para a participação, onde a vontade histórica pela independência ou ao menos uma maior liberdade com relação à Madrid deva ser considerada pois é uma crença substancial destes mesmos participantes. Portanto, uma sociedade democrática participativa decente, que afirme levar em conta o anseio de seus cidadãos, deve levar em conta a aspiração à independência. Já Habermas pode ser utilizado para derivar uma crítica negativa ao processo. Veremos por quê. 
Habermas, como vimos, formula sua teoria deliberativa da democracia após ponderar sobre as qualidades e defeitos das teorias liberais e republicanas. Ao analisarmos o referendo sob os olhos positivos da teoria republicana, podemos contrapô-la com a própria crítica negativa feita por Habermas, concernente ao "[...] idealismo excessivo que há em tornar o processo democrático dependente das virtudes de cidadãos orientados para o bem comum" (HABERMAS, 1995, p. 44). Aqui, duas considerações podem ser feitas: a adoção radical desta autocompreensão coletiva pode se chocar com a liberdade negativa e a importância dada pelo liberalismo à asseguração das liberdades individuais. Se, num contexto de pluralismo, adotarmos a visão da maioria acerca da autocompreensão ética dos valores da comunidade, a intersubjetividade - e possivelmente os direitos - das minorias vão ser prejudicados. Uma concepção liberal não aceitaria isso. Segundo, apoiando-se não na concepção liberal, mas na concepção de Habermas, podemos criticar o referendo ao passo que desconsiderou certas condições de comunicação "[...] sob as quais o processo político pode ter a seu favor a presunção de gerar resultados racionais, porque nele o modo e o estilo da política deliberativa realizam-se em toda sua amplitude" (idem, p. 45). A desconsideração se refere à relevância comunicativa daqueles que se sentem como cidadãos espanhóis, não vendo no processo a manifestação ética de seus interesses. Esta conclusão se fortalece quando vemos que votaram aqueles que já acreditavam nos preceitos separatistas, querendo, assim, a independência, diminuindo o número geral de votos e toda a legitimidade do processo. Além disso, muitas pessoas contrárias à independência podem ter ficado em casa ao saberem que o voto era ilegal.

A questão da legitimidade também surgiu em 2014, quando os catalãos votaram, no dia 09 de novembro, num referendo simulado que pretendia ver quantos catalãos queriam a independência da Espanha. Lá, tivemos os seguintes números (POZZEBON, 2014):

Figura 1: Votação na Catalunha

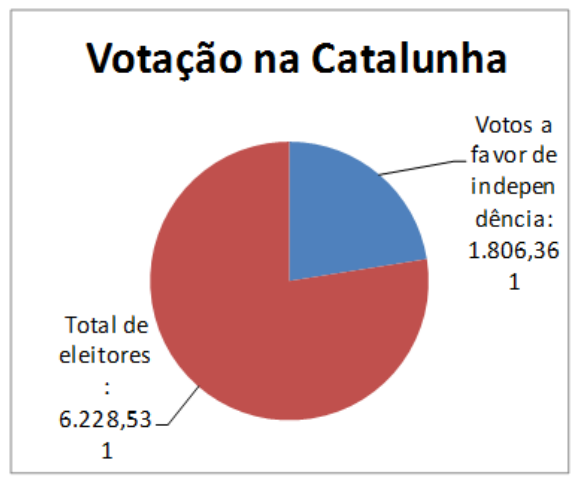

Fonte: Elaborado pelo autor 
No final, somente um terço dos catalãos elegíveis a votar realizaram de fato seu voto.

Continuando na interpretação republicana, Pettit (1999), que entendeu liberdade como não-dominação arbitrária do Estado, também pode providenciar uma interpretação favorável ao referendo. Na sua concepção, liberdade não está circunscrita à ausência de interferência, mas também a ausência de arbitrariedade (estado onde não se leva em conta a autonomia e escolha dos outros). Um de seus interesses centrais nesta obra é compreender como o Estado pode ser organizado de forma que a interferência estatal não produza arbitrariedade, ou produza uma arbitrariedade mínima. Relacionando sua teoria com as motivações separatistas, podemos ver, novamente, como o republicanismo pode lhes fundamentar. O argumento dado pelo movimento de Carles Puidgemont de que a Catalunha tem um direito moral, econômico, cultural, e político, à autodeterminação, pode ser amparado pelo argumento que o governo espanhol desempenhava uma função de imperium, interferindo arbitrariamente na Catalunha. Tomemos o caso ocorrido em 2010, em que a corte constitucional espanhola reescreveu 14 artigos do estatuto de autonomia e disputou a interpretação de mais 27 . Neste momento, não foi dado significado legal à menção da Catalunha como nação e não é dado o mesmo status à língua catalã que aquele conferido à língua espanhola. Logo depois deste evento, que ocorreu dia 28, desenrolaram-se protestos em Barcelona que reuniram mais de um milhão de cidadãos cujo objetivo foi contestar a decisão da corte (GUÀRDIA, 2017).

Juntando a isto a visão de Giacomo Marramao (1993) que, ao perscrutar os paradoxos do universalismo, acabaram por negar a identidade e identificação, suprimindo o vínculo histórico-cultural específico que os indivíduos formam com suas comunidades em prol de uma concepção transcendental do indivíduo. Marramao encontra paradoxos de dois tipos no universalismo: o primeiro, que diz respeito aos paradoxos inerentes à estrutura idealconceitual e o segundo, que é relativo aos paradoxos inerentes à dinâmica e à experiência histórica. Sem adentrar nos pormenores de sua análise, ressaltaremos que no primeiro paradoxo, a lógica do pertencimento a uma comunidade e, posteriormente, excluindo a identidade com a mesma. Mais uma vez, formular uma defesa da independência. $\mathrm{O}$ universalismo poderia representar a continuidade da Catalunha sob o governo espanhol, governo este que negligenciou as diferenças histórico-culturais da região, e parece nunca ter admitido por completo seu status de autonomia.

Até então, tirando uma possível análise habersiana, todos os argumentos foram postos a favor do referendo e da independência. Será este o único caminho possível, com as forças da argumentação de viés participativo, republicano, e comunitarista sobrepujando aquela de 
natureza liberal ou deliberativo? Ou, destes três vieses, todos eles nos levam necessariamente ao apoio? Para responder essas perguntas, voltemos aos fatos e à teoria.

Sobre a primeira pergunta, podemos afirmar que tais teorias são mais ambíguas do que podem ter parecido. Uma das preocupações centrais na teoria participacionista é, como foi visto, a criação de locais onde a participação pudesse ser desenvolvida e aprimorada, além da constante educação acerca dos assuntos que passarão por deliberação. A questão é: houve o debate necessário sobre as consequências e variáveis envolvidas na independência? Ademais, criaram-se lugares onde este debate pudesse ter florescido? $\mathrm{O}$ debate atencioso e rigoroso não é uma mera frivolidade: é, na verdade, um dos aspectos mais importantes de todo processo. Sem este debate, como fazer decisões minimamente conscientes e racionais? O sentimento de não pertencimento e as possíveis injustiças, tão alegados pelos defensores da independência, implicam necessariamente na independência? Não, pois o que está em questão aqui poderia ter sido alcançado com uma maior autonomia, não com a independência. Esta maior autonomia poderia ser alcançada com um maior diálogo com Madrid, no entanto, seja no passado ou no presente, o governo espanhol reagiu, no melhor dos casos, com indiferença, e no pior, com autoritarismo. A resposta autoritária e truculenta do governo espanhol certamente não colaborou, aguçando o sentimento de alienação e domínio arbitrário exterior. O exercício de um diálogo devidamente democrático por parte de Madrid poderia, também, quebrar a situação de imperium conforme descrita por Petit. A arbitrariedade poderia ter sido, senão desfeita, ao menos minimizada, se o governo espanhol tivesse levado em consideração os interesses e escolhas dos catalãos.

E a respeito da heterogeneidade cultural defendida pelos multiculturalistas, ela é satisfeita quando se procura a independência? Mais detalhadamente, seguindo a definição de Miguel (2005) de multiculturalismo como “[...] política da diferença, cujo fundamento é a afirmação das características distintivas dos diversos grupos presentes na sociedade nacional, entendidas como irredutíveis a uma identidade única e fontes legítimas de ação política" (MIGUEL, 2005, p. 08), podemos aplicar a própria definição contra o processo, i.e., ver se o referendo satisfaz as condições colocadas por uma teoria multicultural. Ainda no texto de Miguel, vemos que o multiculturalismo se colocou como a "política da diferença", reafirmando heterogeneidade cultural e a legitimidade dos grupos na arena política. Alguns desses grupos, diz o argumento, foram oprimidos e dominados, portanto, precisam ser protegidos por direitos específicos que funcionarão como um mecanismo reparador das injustiças passadas. Até aqui, nada muito controverso (algumas pessoas poderiam objetar o consequente da condicional, que afirma que esses grupos precisam ser protegidos por direitos 
específicos). Um liberalista rawlsiano poderia facilmente concordar com estes pressupostos. Onde está, então, a controversa?

Entra-se num terreno escorregadio quando se dá uma maior prioridade à diferença do que à igualdade. Um dos maiores feitos do liberalismo (tanto clássico quanto contemporâneo, de inspiração rawlsiana) foi ter realizado a defesa de uma igualdade formal que não restringe as diferenças e desigualdades (não no sentido econômico) presentes na realidade. Os supostos paradoxos do universalismo liberal descrito por Marramao são, pelo contrário, as principais forças da teoria liberal. Ela teve que supor um indivíduo transcendental para fundamentar a própria ideia de direitos humanos, pois estes direitos não dependem de circunstâncias histórico-culturais específicas, servindo não para pessoas que atendem uma coleção de descrição, mas sim são aplicáveis a qualquer pessoa e qualquer contexto específico porque são regras éticas formais, não materiais e consequencialistas. O que quero dizer é: não importa se você é $\mathrm{x}, \mathrm{y}$, ou z, você está defendido pelos direitos humanos, pois, a partir do momento que você é uma pessoa, você está defendido por eles, não importando o lugar ou contexto. $\mathrm{O}$ caso dos direitos humanos exemplifica uma das maiores forças do argumento liberal, que é sua transcendência e formalidade, onde a universalidade formal permite as contingências da vida real. No liberalismo, a igualdade e neutralidade é defendida pois ela é a salvaguarda da diferença. Sobre neutralidade, não quero dizer que não há o comprometimento com uma variedade de crenças, mas sim o que se afirma é que há um comprometimento com crenças justas e gerais, que permitam que indivíduos sigam suas vidas sob um conjunto de princípios básicos.

Passemos, agora, da igualdade para a diferença, qual será o estado de coisas? Primeiramente, não podemos falar em direitos humanos ou liberdades básicas individuais como dados transcendentais, i.e. não empíricos, e universais, sem entrar em contradições. Afinal, como defender algo que formalmente é contra as especificidades histórico-culturais de cada local? Coloca-se como correto, à vista disto, princípios defendidos por certa comunidade, isto é, princípios cuja formulação depende da adoção de aspectos culturais específicos defendidos pela comunidade. Isto é possível? É possível uma comunidade A formular ou alcançar consensualmente uma classe de princípios xyz? O famoso paradoxo de Condorcet, ao afirmar que grupos de maiorias podem entrar em conflito, mostra a dificuldade de se organizar preferências mesmo quando os indivíduos que compõem o grupo têm desejos consistentes. Ou, ainda assim, mesmo que grupos organizem suas preferências, o que dizer daqueles membros deste grupo que não concordam com aquilo decidido pelo grupo? Devem se sujeitar àquilo decidido pelo grupo? Observemos um caso de um país como à Espanha, 
com uma enorme diversidade cultural manifestada, por exemplo, numa grande heterogeneidade linguística. O problema é que, mesmo que consigamos delinear traços culturais gerais de cada grupo, fazemos isso com certa dificuldade e logo admitimos que nosso delineamento é ideal, pois excluímos uma série de manifestações culturais diferentes ou até mesmo contrárias aos tidos traços gerais. É justo que essas manifestações culturais distintas aceitem a decisão de um grupo que adota as opiniões culturais majoritárias?

Um dos problemas centrais da visão exposta acima é o fato de sua crítica ao atomismo societário criado pelo liberalismo trocar um atomismo individualista por um atomismo grupal. Se cada grupo pode - e talvez deva - se sentir diferente, pois há características cuja manifestação é própria àquele grupo e não outro, o que será da sociedade? O que será dos Estados-nacionais? Ou, como consequência, imaginemos um grupo A com características culturais gerais xyz. Admitamos que nem todos podem coadunar com essas características; de fato, mesmo que a maioria as aceite, ainda assim boa parte pode não as aceitar. Estamos repetindo o argumento da sujeição da minoria, mas precisamos ressaltar que ela não se restringe ao momento decisório, passando também pelo convívio cotidiano desses indivíduos, pois há o risco desse grupo tratar aqueles que defendem suas crenças de um modo especial, menosprezando aqueles que não o fazem. Em outras palavras, podemos algo semelhante ao populismo contemporâneo e em algumas de suas manifestações históricas: a criação de cidadãos "verdadeiros", em contraposição aos "falsos". Os verdadeiros são aqueles que aceitem um sistema de crenças, os falsos os que não aceitam. No caso da Catalunha, podemos ter a criação de um discurso que coloque o verdadeiro catalão como aquele que defende a independência, vendo quem não faz com suspeita.

Com todos estes argumentos apresentados, podemos decretar o fim de toda teoria multicultural, ou somente de certa vertente que coloca os requisitos de integração como “imperialismo cultural”? Vejamos, acerca do multiculturalismo, a análise de Kymlicka (1996) nos apresenta um de seus principais objetivos: o fato das sociedades modernas terem que dar conta e acomodar diversas identidades culturais. Kymlicka nos dirá que o multiculturalismo não está necessariamente comprometido com a separação em guetos culturais, pelo contrário: afirma que a diversidade cultural pode surgir a partir da coexistência, dentro de um determinado Estado, de mais de uma comunidade histórica. $\mathrm{O}$ autor dá o nome de nações a essas comunidades históricas de cultura minoritária, e afirma que podem existir - e de fato existem - Estados multinacionais. Ademais, afirmar que certos países são multinacionais não implica dizer os cidadãos não se considerem um povo único. Este tipo de multiculturalismo é mais aceitável pois escapa dos problemas erigidos pela colocação da diferença como objetivo 
final. Ela aceita um substrato de igualdade ao colocar que, apesar dessa coexistência de diversas comunidades históricas, formando um Estado multinacional, eles ainda se consideram como membros de um único país. Deste modo, um multiculturalismo moderado, ainda comprometido com a noção de igualdade, é mais válido do que a versão apresentada anteriormente. No caso espanhol, este tipo de multiculturalismo ainda manteria a união nacional; o que faria, na verdade, seria conferir uma maior autonomia à Catalunha. Esta possibilidade de asseguração de maior autonomia a partir do diálogo foi discutida anteriormente quando se abordou a teoria participacionista.

\section{Considerações finais}

Como conclusão, podemos ressaltar a falta de diálogo e preparo como fortes obstáculos à defesa da independência. Após isso, as consequências já abordadas de um multiculturalismo mal formulado podem gerar a separação da sociedade em grupos culturais distintos, onde cada um exige sua separação do outro. Apesar do anseio por uma maior autonomia dever ser levado a sério, disto não se retira que a independência seja a única solução possível. Pelo contrário, um maior diálogo com Madrid poderia garantir aquilo que uma independência faria sem as consequências drásticas desta última. Ressalta-se, também, a falta de legitimidade de todo processo no que concerne à quantidade de pessoas que foram votar. Como se viu, somente aqueles já convictos pela independência foram votar, ou seja, apesar deles terem vencido, a participação dos eleitores não foi suficiente para conferir força ao processo

AGRADECIMENTOS: Agradeço à Fundação de Amparo à Pesquisa do Estado de São Paulo pelo financiamento de bolsa de iniciação científica. Apesar do tema deste artigo não estar relacionado com meu projeto de pesquisa, a bolsa concedida pela FAPESP é um grande incentivo à atividade intelectual rigorosa, seja lá qual assunto.

\section{REFERÊNCIAS}

BENAVIDES, L. Market Place. Disponível em <https://www.marketplace.org/2017/09/29/economy/big-reason-catalonia-wants-secedeeconomic-richest-regions-in-spain>. Acesso em: 02 dez. 2017.

GOVERNO DA CATALUNHA. Disponível em:

$<$ http://premsa.gencat.cat/pres_fsvp/AppJava/notapremsavw/303541/ca/govern-trasllada- 
resultats-definitius-referendum-11-doctubre-parlament-catalunya.do>. Acesso em: 25 nov. 2017.

GUÀRDIA, B. A. Político. Disponível em: <https://www.politico.eu/article/cataloniareferendum-independence-timeline-how-did-we-get-here/>. Acesso em: 02 dez. 2017.

HABERMAS, J. Três modelos normativos de democracia. In: Lua Nova. São Paulo, $\mathrm{n}^{\circ}$ $36 / 1995$.

KYMLICKA, W. Ciudadanía multicultural - una teoría liberal de los derechos de las minorías. Barcelona: Paidós, 1996.

MARRAMAO, G. Paradoxos do universalismo. Indivíduo e comunidade na idade global. In: (Vários autores). Liberalismo e socialismo: velhos paradigmas. São Paulo: Editora da UNESP, 1995, p.131-147.

MICHELS, R. Os partidos políticos. Brasília: UNB, 1982

MIGUEL, L. F. Teoria democrática atual: esboço de mapeamento. In: BIB - Revista Brasileira de Informação Bibliográfica em Ciências Sociais, São Paulo, v. 59, 1o semestre de 2005.

PATEMAN, C. Participação e teoria democrática. Rio de Janeiro: Paz e Terra, 1970.

PETTIT, P. Republicanismo - Una teoría sobre la libertad y el gobierno. Barcelona: Paidós, 1999

POZZEBON, S. Business Insider UK. Disponível em:

<http://uk.businessinsider.com/catalan-independence-referendum-2014-11>. Acesso em: 02 dez. 2017.

SCHUMPETER, J. A. Capitalismo, socialismo e democracia. Rio de Janeiro: Zahar Editores, 1984.

THE ECONOMIST. The Economist. Disponível em:

<https://www.economist.com/blogs/economist-explains/2017/09/economist-explains-17>.

Acesso em: 25 nov. 2017.

WILDMAN, S. Vox. Disponível em:

<https://www.vox.com/world/2017/10/2/16393956/catalonia-catalan-independencecrackdown-vote-referendum>. Acesso em: 25 nov. 2017.

\section{Como referenciar este artigo}

MOTTA, Caio. Teorias da democracia e o referendo catalão de 2017. Rev. Sem Aspas, Araraquara, v.6, n.2, p. 196-209, jul./dez., 2017. ISSN: 2358-4238. 